\title{
EL SEGUNDO ESTILO POMPEYANO. Aproximación a SUS Sistemas DE PERSPECTIVAS
}

\author{
Belinda Martín Porras
}

Universidad Complutense de Madrid

RESUMEN: El grado de ilusionismo tridimensional alcanzado durante el segundo estilo de la pintura romano-campana fue posible gracias al uso de varios sistemas de perspectivas, los cuales se aplicaron premeditadamente en zonas concretas de la superficie parietal para generar efectos ópticos y dramáticos sobre el observador. Nos centraremos en los dos principales tipos de perspectiva que emplearon los muralistas romanos del siglo i a. C. - I d. C.: la perspectiva convergente y la paralela, así como en su aplicación en otros medios que desempeñaron una función análoga, como fueron las pinturas escenográficas (skenographia) y los dibujos de los arquitectos (scenographia).

Palabras clave: perspectiva antigua, pintura pompeyana, segundo estilo pompeyano.

Abstract: The impressive skill and degree of perfection that was achieved in the three dimensional architectonic paintings during the so-called Second Style of Roman Wall painting were made posible by the use of several different perspective systems. Those were combined and used in different parts of the wall with the sole purpose of generating dramatic effects in the observer. We analyze the two main types of perspectives used by Roman wall painters during the $1^{\text {st }}$ century B.C.E: the convergence and the parallel perspective that shows how the painter adapted the different perspective types to the physical and social characteristics inherent to the roman domus and villa. Also, we analyze the use of these types of perspective in other fields such as the scenery paintings (skenography) and the Roman architectural plans (scenography). 
Keywords: ancient perspective, Roman wall painting, second style Roman wall painting.

\section{INTRODUCCIÓN ${ }^{1}$}

$\mathrm{E}_{\mathrm{p}}^{1}$ progresivo interés por plasmar pictóricamente una selección verosímil presente en la naturaleza tuvo en la gestación de sistemas de perspectiva uno de sus grandes epítomes, los cuales se desarrollaron paulatinamente desde el siglo v a. C. en Grecia hasta alcanzar las cotas de verosimilitud tridimensional que presentan muchos ejemplos de pinturas pertenecientes al segundo estilo pompeyano. Periodo estilístico en que el desarrollo de la perspectiva mostró los mejores frutos no solo de la tradición que parte de la pintura helenística - por lo demás, manifestación que nos es prácticamente ajena a excepción de unos cuantos ejemplos conservados-, sino también de los avances cultivados en el campo de la geometría y la óptica capitaneados por figuras como Demócrito y Anaxágoras. ${ }^{2}$ Por ello, el cometido del presente escrito no es otro que esbozar los diferentes tipos de perspectiva empleados en el segundo estilo pompeyano, por ser este el estilo pictórico romano conocido que más se detuvo en representar esta veracidad tridimensional de la physis que venimos tratando, para después analizar los ejemplos más idiosincráticos de cada fase pictórica.

Los motivos y asuntos representados en el segundo estilo pompeyano dan cuenta no solo de la nueva koiné -impregnada en todos los niveles de la helenizada sociedad romana - que sobrevino a la cuenca del Mediterráneo al compás de las conquistas territoriales de la joven República romana, sino del grado de experimentación técnica y extravagancia estética con que fueron concebidos. El lujo constructivo, ${ }^{3}$ connatural al urbanismo helenístico, dejó

1. La etiqueta de "pintura pompeyana» ha sido utilizada indistintamente para hacer referencia tanto a la pintura gestada en Pompeya y sus «ciudades satélites» (vid. Herculano, Boscotrecase, Oplontis y Boscoreale), como a la procedente de Roma. El mismo trato ha recibido la denominación de «pintura romana»; a la que habría que sumar la de «pintura romano-campana» que, ciertamente, es la más precisa pero que por economía de palabras es la que menos prolifera.

2. No obstante, en esta plasmación plástica de las leyes matemáticas que rigen en la naturaleza contribuyeron los propios pintores también desde el ámbito teórico, no solo práctico, cultivando la teoría de su arte. Recuérdese la afirmación pliniana según la cual el pintor «Pánfilo, maestro del gran Apeles, era un destacado matemático y sostenía que no se puede ser un buen artista sin conocer la aritmética y la geometría». Así como los numerosos tratados de pintores: De la pintura de Parrasio o los escritos «sobre la pintura de escenarios que, a raíz, de sus efectos de ilusionismo, provocó en su tiempo animadas discusiones» en WŁadysŁaw TAtarkiewicz: Historia de la estética I: La estética antigua, Akal, Madrid, 1987, pp. 54, 65.

3. Traducido arquitectónicamente en la multiplicación de stoai, la monumentalización de los edificios, particularmente de espectáculos; la dignificación de los gymnasia y salas de reunión o la creación de nuevos edificios con funciones específicas (vid. mercados, bibliotecas, etc.), en Miguel Ángel Elvira: Manual de arte griego. Obras y artistas de la Antigua Grecia, Sílex, Madrid, 2013, p. 319. 
una impronta notable en la decoración de las domus y villae de las grandes figuras públicas del periodo tardorrepublicano, fenómeno del que, sin duda, los romanos tomaron nota a medida que sus relaciones con el mundo helenístico se fueron estrechando. Paralelamente, en el siglo il a. C., surge en los grandes centros artísticos del Mediterráneo oriental (Atenas, Pérgamo y Rodas) una tendencia artística clasicista que, a partir de entonces, se extiende sin fisuras hasta época romana.

Ciertamente, el punto hasta el cual las casas romanas fueron pintadas -a excepción de cocinas, baños y habitaciones de almacenaje- supera con creces el de sociedades posteriores, como evidencian los restos excavados en Pompeya y Herculano, ciudades relativamente prósperas aunque no excepcionales. ${ }^{4}$ Factor que permite extrapolar el alcance de la pintura parietal en las grandes urbes como Roma, ciudad en la que los escasos ejemplos conservados evidencian como en ningún otro lugar del Imperio la vanguardia estética dominante. Como cabe esperar, las habitaciones más nobles de la casa romana de alto estatus contaban con la decoración pictórica más exquisita: el atrium, el tablinum, el peristilo, los oeci y triclinia. Estancias que gozaban de las pinturas de mayor calidad, riqueza cromática, complejidad ornamental y abundancia de escenas mitológicas. Por el contrario, en las habitaciones secundarias (Nebenzimmer), como las de los esclavos, no siguieron estilo pompeyano alguno, limitándose a monótonos patrones compuestos a base de bandas y rayas sin interés artístico alguno. ${ }^{5}$ Así, la relación del espacio arquitectónico para el que fue concebida la pintura es otro asunto primordial para entender la lógica que descansa detrás de la elección no ya de una corriente o moda estética, sino de un sistema de perspectiva específico. ${ }^{6}$

\section{La pintura romano-campana}

El asunto de los tipos de perspectiva conocidos en la Antigüedad, así como de las artimañas empleadas por los artistas para generarlos, ha provocado opiniones contrapuestas desde las últimas décadas de la era decimonónica,

4. Roger Ling: Roman Painting, Cambridge, University Press Cambridge, 1951, p. 2.

5. Volker Michael Strocka: «Pompejanische Nebenzimmer», en Bernard Andreae, Helmut Kyrieleis (ed.): Neue Forschungen in Pompeji un den anderen von Vesuvausbruch 70 n.Chr, verschütteten Städten, Recklinghausen, 1975, pp. 101-114.

6. En este sentido, conviene fijarse en aspectos de los que, poco a poco, se va teniendo un conocimiento mayor y exacto -gracias al avance en las excavaciones arqueológicas de las ciudades vesubianas, principalmente-, tales como la adaptación al espacio, la funcionalidad de la estancia dentro de la pequeña microcélula de representación que es la domus romana, o de las grandes villas destinadas al mero cultivo del disfrute; las fuentes lumínicas y su grado de incidencia, así como la decoración de suelos y techos, para la que se destinaron estucos, mosaicos, estatuas y el mobiliario. Sin desestimar el papel que jugaron patrones y artistas, cuyo gusto y capacidad de artificio permitieron crear las composiciones espaciales más avanzadas de su época, en ANDrew Wallace-HAdrill: «Patronage in Roman society: from Republic to Empire», en ANdrew Wallace-Hadrill (ed.): Patronage in ancient society, Routledge, Londres, 1989, pp. 63-88. 
cuando August Mau publicó su consabido estudio sobre la pintura pompeyana, ${ }^{7}$ proponiendo la taxonomía estilística de la que se han nutrido los estudiosos desde entonces, basada, grosso modo, en el grado de tridimensionalidad alcanzado. Un breve análisis de los diferentes modos que manejaron los artistas griegos para superar el carácter bidimensional inherente a los soportes en que se desarrolló habitualmente la pintura -a reducir por su distribución, básicamente, en el parietal y cerámico-,${ }^{8}$ entre los que se encuentra la propia perspectiva, nos servirá para explicar la génesis y formación de los sistemas de perspectiva imperantes en la pintura pompeyana, y que constituyen, desde el punto de vista de quien escribe estas líneas, no solo la culminación de una tradición inaugurada allá por la Grecia clásica del siglo v a. C., sino también la gran aportación de la plástica romana al campo pictórico.

El primero en abordar un estudio detenido de los restos pictóricos diseminados por las antiguas ciudades vesubianas fue Mau, erudito alemán que -siguiendo la estela metodológica para el estudio de obras de arte inaugurada por Johann Joachim Winckelmann (1717-1768) - fue pionero en el establecimiento de una secuencia cronológica ${ }^{9}$ para la pintura romana basada, precisamente, en los notables cambios estilísticos generados en el paso sucesivo de cada uno de los cuatro grandes estilos. Inaugurando, de este modo, la consabida terminología de los estilos pictóricos romanos, la cual se apoya en el potencial o en la capacidad de provocar ilusiones ópticas y de crear efectos tridimensionales en la superficie muraria de tales estilos. De acuerdo con este criterio, Mau denominó al primer estilo Incrustationsstil, pues pretendía imitar las ricas incrustaciones de mármoles polícromos presentes, acaso, en los grandes conjuntos palaciegos helenísticos, constituyendo si bien esta referencia formal su fuente indirecta, lo cierto es que su fuente inmediata fueron las pinturas que ornaban las paredes de casas griegas como las dedálicas.

El rasgo más idiosincrático del segundo estilo (Architekturstil), consiste -como su denominación germana indica- en la profusión de estructuras y marcos arquitectónicos de toda índole que aparecen habitualmente representados en la pintura parietal, los cuales han recibido un tratamiento espacial que provoca verdaderos efectos de trompe-l'oeil. A diferencia de los estilos venideros,$^{10}$ caracterizados por el retorno a la predilección por las superficies, digamos, «planas», el Architekturstil usó extensamente perspectivas

7. August MAu: Geschichte der decorativen Wandmalerei in Pompeji, Druck und Verlag von G. Reimer, Berlín, 1882.

8. Aunque la pintura también se dio en otros medios como los pinakes, una suerte de cuadros cerámicos, pétreos o lígneos- que se colgaban en las paredes de las grandes casas o edificios públicos. En este sentido, notable fue la Stoa Poikíle de Atenas. Tampoco puede olvidarse la función que ocupó la pintura que cubría relieves y esculturas, que sin duda contribuiría, gracias al color y la luz, a generar contrastes volumétricos que enfatizaban los existentes en la realidad hechos por los escultores.

9. El desarrollo formal y estilístico de la pintura romana propuesto por Mau, se produjo entre ca. siglo II a. C. y fines del primer siglo d. C., en Rolf A. Tyвоut: «Roman Wall-Painting and Social Significance», Journal of Roman Archaeology, 14 (2001), p. 37.

10. El tercer («der ornamentale Stil») y cuarto estilos se desarrollaron desde el siglo I d. C., a menudo conviviendo ejemplos paralelos hasta el fatídico 79 d. C., en August Mau, 1982, pp. 289-448. 
arquitectónicas, provocando, por ello, que haya sido el más estudiado dentro de la pintura romana. Así pues, mientras en el segundo estilo la tónica dominante fue el principio del ilusionismo arquitectónico, durante el tercero se creó una suerte de canon ornamental, ${ }^{11}$ que trajo consigo el predominio del color y el gusto por representar estilizados y pequeños detalles ornamentales y figuritas sobre una superficie uniforme, carente de referencia espacial real alguna; mientras que, el cuarto, fue el menos homogéneo y el más ecléctico, tomando indiscriminadamente elementos de sus predecesores y transformándolos en sistemas basados en vistas arquitectónicas irreales -concebidas como si se contemplasen a través de pequeñas aperturas (Durchblicke $)^{12} \mathrm{y}$ que aparecen en lo alto del muro- y en una suerte de «cuadros de caballete colgantes» o tapices en los que se representan escenas figurativas o figuritas flotantes (Vorhänge). ${ }^{13}$

Esta taxonomía fue perfeccionada por el holandés Hendrik Gerard Beyen en su magnífica Die pompejanische Wanddekoration (1938), obra en la que se propuso aportar una clasificación detallada del segundo, tercer y cuarto estilos, pero que, lamentablemente, no llegó a concluir pues solo llegó a desarrollar el esquema evolutivo interno del segundo estilo, ${ }^{14}$ al cual nos remitiremos en líneas posteriores cuando nos detengamos a analizarlo. Salvo ligeras variaciones peregrinas, la mayoría de los estudiosos ${ }^{15}$ han confirmado y adoptado dicha secuencia estilística, la cual también ha venido a ser contrastada por los datos arqueológicos del siglo pasado y presente, obteniendo resultados a favor de la misma.

\section{LA PERSPECTIVA ANTIGUA}

\section{Vitruvio}

¿Qué es la perspectiva? Desde un punto de vista etimológico, la raíz que comparten las palabras latinas perspectiva y prospectiva, «spec», deriva del verbo specio (observar, mirar). Los prefijos per- y pro- pueden traducirse,

11. Roger Ling, 1991, p. 71.

12. El término Durchblick fue acuñado por Heinrich Drerup -en su magistral artículo sobre el espacio pictórico y real en la arquitectura romana-, y que puede traducirse como «vista o ventana a través», exponiendo como ejemplo principal las Durchblicke presentes en la pompeyana Casa del Menandro (I 10, 4), en Heinrich Drerup: «Bildraum und Realraum in der römischen Architektur», Mitteilungen des Deutschen Archäologischen Instituts. Römische Abteilung, 66 (1959), pp. 145-174.

13. ROger LiNG, 1991, pp. 71-100.

14. Hendrik Gerard Beyen: Die pompejanische Wanddekoration vom zweiten bis zum vierten Stil, The Hague, 1938/1960.

15. Hendrik Gerard Beyen, 1938/1960; Frédéric L. Bastet, Mariette de Vos: Proposta per una classificazione del terzo stile pompeiano. Staatsuitgeverij, The Hague, 1979; Werner EHRHARDT: Stilgeschichtliche Untersuchungen an römischen Wandmalereien. Von der späten Republik bis zur Zeit Neros, Von Zabern, Mainz, 1987. 
respectivamente, como «a través de» $\mathrm{y}$ «en conformidad con». Por lo que, en el término perspectiva se incluyen algunas de sus cualidades, literalmente, las de «ver a través de» o de «mirar conforme a» algo. ${ }^{16}$ Sin embargo, ambos vocablos aparecen por vez primera en el siglo vi d. C., ${ }^{17}$ concretamente en el Analyticorum posteriorum Aristotelis interpretatio de Severino Boecio (476-524 d. C.). El estudio de la perspectiva se ha abarcado desde muchas vertientes y de diferentes maneras a lo largo de la historia. Sin embargo, no es hasta bien entrado el siglo xx que empezamos a tener un cierto conocimiento sobre cómo ocurre y qué es exactamente gracias al estudio sistemático de la percepción.

La existencia o no del conocimiento de la perspectiva geométrica en la Antigüedad es una de las grandes problemáticas a que se siguen enfrentando los académicos. La habitual comparación con la perspectiva originada en esa suerte de centuria de intensa experimentación, en todos los niveles y campos, denominada Quattrocento -en que las líneas ortogonales convergen en un punto de fuga-, es un topos en la historiografía artística de la pintura romana. ${ }^{18}$ En este opúsculo el término «perspectiva» será definido como todo intento de expresar la tercera dimensión sobre un plano bidimensional. ${ }^{19}$ Creación que se apoya en varios recursos que la tradición pictórica ha venido usando desde entonces y para los que nos remitiremos a lo antedicho en el apartado precedente.

Grosso modo, la visión convencional asumida por la comunidad académica, desde fines del siglo XIX y principios del $\mathrm{xx}$, en relación a la perspectiva antigua -basada en que los antiguos poseían conocimientos fehacientes de la perspectiva moderna o geométrica- afirmación apoyada, a su vez, en la interpretación de los famosos pasajes vitruvianos referentes a la técnica de la perspectiva (De architectura I. 2. 2; VII) -fue polarizada por dos grandes tendencias abanderadas por dos investigadores imprescindibles para el campo que tratamos. Por un lado, Erwin Panofsky, figura que negó la existencia de la perspectiva geométrica o lineal en la Antigüedad en su brillante ensayo Die Perspektive als «Symbolische Form» (publicado por vez primera entre 192425), cuestionándose la communis opinio decimonónica. Panofsky expuso que la representación espacial «in ancient Greek vase painting and, later, Roman wall painting suffered from the artists inability to portray the foreshortening of objects in a constant stay of distorsion, as scientific one-point perspective

16. Rocco Sinisgalli: Perspective in the Visual Culture of Classical Antiquity, University Press, Cambridge, 2012, p. 3.

17. Los romanos de la época republicana e imperial utilizaban una de las acepciones de la scenographia para designar la perspectiva, según se desprende de ciertos comentarios de Vitruvio, que analizaremos dentro de poco.

18. Véase sobre todo SAMUel Y. Edgerton: The Renaissance rediscovery of linear perspective, Harper and Row, Nueva York, 1976.

19. Miguel Ángel Elvira: «Aportaciones al estudio de la perspectiva lineal en la Grecia del siglo v a. C.», Archivo Español de Arqueología, 56, 147-148 (1983), p. 61. 
does». ${ }^{20}$ Su interpretación del discutido pasaje de Vitruvio (De architectura I. 2. 2), fue determinante para argumentar tal afirmación:

Item scaenographia est frontis et laterum abscedentium adumbratio ad circinique omnium linearum responsus. ${ }^{21}$

Esta última fórmula ha sido el detonante de la interpretación tradicional, que extrae del texto vitruviano este punto de fuga central al que «omnium linearum responsus», opinión que apenas goza de respaldo en la actualidad. ${ }^{22}$ A su vez, otros han asumido una equivalencia conceptual entre las líneas ortogonales a que se refiere Vitruvio -fundamentales para la construcción de la perspectiva de que venimos hablando-y los rayos de visión «that meet at the apex of the visual cone», ${ }^{23}$ tal como definieron Euclides y Lucrecio en sus conocidas obras. ${ }^{24}$ Vitruvio hace referencia a la scenographia, adoptando el término en su sentido estricto como «método de representación perspectiva de los edificios sobre una superficie, o bien con fines arquitectónicos, o bien teóricos», ${ }^{25}$ es decir, según Vitruvio la scenographia (perspectiva) constituye uno de los componentes del sistema de representación empleado por los arquitectos romanos para el dibujo de edificios, a los que habría que añadir la ichnographia (planta) y la ortographia (alzado). En este sentido, es significativo el que Vitruvio haya unido este concepto de scenographia con la skenographia griega ${ }^{26}$ ( $\left.\sigma \kappa \eta v o \gamma \rho \alpha \varphi i \alpha\right)$. Términos que si bien están emparentados claramente etimológicamente, no tanto conceptualmente. Precisamente, la convergencia de ambas tradiciones por parte de Vitruvio aparece en el otro polémico pasaje

20. Philip Stinson: «Perspective Systems in Roman Second Style Wall Painting», Journal of the Archaeological Institut of America, 115, 3 (2011), p. 406; ERWIN PANOFSKY: La perspectiva como «forma simbólica», Tusquets, Barcelona, 2010, pp. 21-28.

21. «La perspectiva es el bosquejo de la fachada y de los lados alejándose y confluyendo en un punto central de todas las líneas», según la traducción del latín de José Luis Oliver (trad.): Los diez libros de Arquitectura, Alianza Editorial, Madrid, 1995, p. 89.

22. Pierre Gros: "The Theory and Practice of Perspective in Vitruvio's De architectura», en Mario Carpo, Frédérique Lemerle (eds.): Perspective, Projections and Design. Technologies of Architectural Representation, Routledge, Nueva York, 2008, p. 17.

23. Philip Stinson, 2011, p. 406.

24. Vid. los dos primeros postulados de la Optica de Euclides: «Supóngase que las líneas rectas trazadas a partir del ojo se propagan a lo largo de un espacio de grandes magnitudes. Y que la figura contenida por los rayos visuales es un cono que tiene el vértice en el ojo y la base en los extremos de los objetos vistos», en Euclides: Optica (Paloma Ortiz, (trad.): Óptica, Gredos, Madrid, 2000, p. 134); Lucrecio, De rerum natura, 4, 426-31.

25. ERWin PANOFsky, 2010, n. 117.

26. Literalmente significa «pintura de escenas». Su mención más temprana se remonta a la Poética de Aristóteles (1449a18), es decir, al siglo IV a. C., en la que se cuenta que Sófocles -dramaturgo que Vitruvio sustituyó por Esquilo- ya la empleaba en la representación de sus obras. Sin embargo, resulta «unclear what the nature of skenographia was at the time of its birth in the fifth century BCE and where precisely it was placed on the skene», en Jocelyn Penny Small: «Skenographia in brief», en George W. M. Harrison, Vayos Liapis, (eds.): Performance in Greek and Roman Theatre, Brill, Leiden, 2003, p. 111. Asimismo, de los comentarios vitruvianos, se desprende que la skenographia griega fue una técnica inventada para la representación de estructuras arquitectónicas en las pinturas de escenarios expuestas en los teatros griegos desde el siglo v a. C., en Philip Stinson, 2011, p. 406. 
(De arch. VII) que, al igual que el anterior, nos permite «sospechar la existencia de una perspectiva pictórica de construcción matemática»:27

Agatarco fue el primero que ejerció como director de escena en Atenas, mientras Esquilo representaba sus tragedias (...) Demócrito y Anaxágoras escribieron también sobre esta misma cuestión: la manera más convincente de que se correspondan unas líneas imaginarias trazadas desde un centro fijado, con la proyección de los rayos visuales y con la dirección de la vista; y todo, de manera natural, con el fin de que unas imágenes insinuantes de un insinuante objeto consigan apariencia de auténticos edificios en los decorados del escenario y con el fin de que los elementos que aparecen dibujados en superficies verticales y planas, parezca como que están alejados o que están próximos. ${ }^{28}$

No obstante, unos capítulos más hacia delante (De arch. VII.5.2), Vitruvio proporciona el nexo de unión entre estas dos tradiciones -la de la representación gráfica en perspectiva de los edificios y la griega de pinturas de escenarios-con la pintura romana, al expresar que en determinadas estancias de la casa romana se debía representar «los frentes de escenarios, decorados para tragedias, comedias o sátiras». ${ }^{29}$ Vitruvio estaba describiendo aquí, efectivamente, el segundo estilo pompeyano, que le era contemporáneo, pues comenta que, siguiendo un proceso evolutivo, se «empezaron a representar las formas de los edificios, el relieve de las columnas y el vuelo de los frontones». ${ }^{30}$ En resumen, son los términos antiguos que más se aproximan a nuestra moderna perspectiva renacentista, a los que algunos añaden el de skiagraphia, técnica que -pese a que también genera perspectiva- emplea un método basado en el sombreado (véase la llamada pintura de sombras) y no en una aproximación a la idea del punto de fuga.

Asimismo, tras este excursus vitruviano, conviene cerrar el planteamiento sobre la perspectiva expuesto por Panofsky, para quien la escasez o, mejor dicho, poco interés demostrado en el espacio perspectívico que evidencian las representaciones del arte griego prehelenístico se debe al intenso antropocentrismo del que - parece ser- padecieron los griegos; fenómeno que contrapone a la cultura romana, en la que el tratamiento tridimensional del espacio se desarrolló libremente, ${ }^{31}$ aunque adoptando un principio de

\footnotetext{
27. Erwin PANOFsky, 2010, n. 119.

28. JosÉ Luis Oliver (trad.), 1995, p. 257.

29. Ibid., p. 273

30. Id.

31. Compárese este presupuesto con el análisis realizado por Schweitzer sobre los citados conceptos de Körperperspektive y Raumperspektive, los cuales contrapone y que, además, guardan concomitancias con el enfoque defendido por Panofsky al respecto, así describe el académico de Hannover el arte de la Antigüedad clásica: como un «mero arte de cuerpos» que «reconocía como realidad artística no solo lo simplemente visible, sino también lo tangible y no unía pictóricamente los diversos elementos, materialmente tridimensionales y funcional y proporcionalmente determinados, en una unidad especial, sino que los disponía tectónica o plásticamente en un ensamblaje de grupos. Y aun cuando el Helenismo (...) no concibe el espacio como algo capaz de circunscribir y resolver la contraposición entre cuerpos y la ausencia de estos, sino, en cierto modo, como aquello que permanence entre cuerpos», en ERWIN PANOFSKY, 2010, p. 25.
} 
representación espacial que vino a comparar con la espina dorsal de los peces -haciendo uso de una analogía formal- y que denominó el principio del eje de fuga, en base al cual las prolongaciones de las líneas de profundidad «no convergen rigurosamente en un punto, sino que se encuentran (...) convergiendo solo débilmente de dos en dos en diversos puntos, situados todos sobre un eje común», ${ }^{32}$ produciendo la consabida impresión formal.

\section{Estado de la cuestión}

Por otro lado, Beyen fue uno de los primeros en contrastar los datos procedentes de las fuentes literarias grecorromanas con el análisis extenuado de las pinturas del segundo estilo. En su citado estudio, que versa sobre el entendimiento de la perspectiva, se centró especialmente en la recién descubierta Villa de los Misterios, y propuso que los escenógrafos griegos sí manejaron una rigurosa forma de perspectiva, dependiente de principios matemáticos, y que los mecanismos empleados en el Architekturstil en la construcción de la perspectiva -llevados a cabo por simples Dekorateure-, fueron meros intentos aproximativos de imitar la skenographia griega desplegada en los teatros helenos. Ergo, deshaciendo este discurso argumental, se entiende que, para Beyen, el despliegue arquitectónico presente en el segundo estilo deriva de los decorados escenográficos que solían ubicarse en los escenarios teatrales griegos, opinión que no ha sido siempre compartida por la comunidad académica. Sin embargo, Beyen llegó a sugerir que algunas de las pinturas halladas en la Villa de los Misterios muestran «a theoretical and practical knowledge of geometrically unified perspective». ${ }^{33}$ Por ello, pese a la agitación que sus observaciones y conclusiones provocaron en la todavía escasa historiografía artística de la perspectiva en la pintura pompeyana, lo cierto es que vinieron a constituir la base de futuras aportaciones al asunto.

Paralelamente, durante la década de los años veinte del siglo pasado, se han ido sucediendo investigaciones que han tenido en cuenta el contexto cultural en que se produjeron tales manifestaciones artísticas. Aspecto fundamental para intentar dilucidar la intención que descansa tras la elección no solo de temas y motivos de índole estilístico, sino de los sistemas de perspectiva distribuidos en zonas concretas de la superficie muraria de ciertas estancias de la casa romana; ya que, además del valor formal y estilístico de la pintura pompeyana, el grado de incidencia o el tratamiento tridimensional del plano pictórico dan cuenta, a menudo, de las distintas pautas de comportamiento humanas, las cuales pueden ser taxonomizadas en los siguientes niveles: el

32. Erwin Panofsky, 2010, pp. 22-23.

33. Philip Stinson, 2011, p. 407; Hendrik Gerard Beyen, 1938, pp. 61-88; Hendrik Gerard BEYEN: «Die antike Zentralperspektive», Jahrbuch des deutschen archäologischen Instituts, 54 (1939), pp. 47-72. 
tecnológico, el económico-social y un tercero de significación más profunda, que engloba el sistema de creencias de una sociedad concreta. En esta cosmogonía o Weltanschauung se engloban las fuentes literarias existentes, gracias a las cuales se pueden completar las funciones sociales desempeñadas por la casa romana, de las que, naturalmente, es partícipe la decoración que en ellas se produjo.

En este sentido, supuso un avance significativo en el campo la obra de Phyllis W. Lehmann: Roman Wall Paintings from Boscoreale in the Metropolitan Museum of Art (1953), en la que su autora criticó la asunción de que el único método con que contaron los antiguos para crear la impresión de espacialidad en una superficie bidimensional fuese la supuesta perspectiva monofocal, abriendo la posibilidad de que los pintores romanos no es que no tuviesen los recursos prácticos y teóricos para crear una perspectiva basada en preceptos matemáticos, sino que, sencillamente, su ejecución no se hallaba entre sus propósitos, los cuales les habrían llevado a adoptar una serie de convenciones pictóricas ajenas a nuestro ojo moderno. ${ }^{34}$ Asimismo, destaca la aportación de Decio Gioseffi, quien en su pequeño libro Perspectivas artificiales (1957) señaló la importancia del espacio arquitectónico real en que se ubicaban las pinturas, el cual supuso un condicionante a tener en cuenta a la hora de diseñar los juegos ópticos de que se nutren los sistemas de perspectiva.

Asumiendo las directrices postuladas por Heinrich Drerup, ${ }^{35}$ Burkhardt Wesenberg acuñó el término assymetrische Perspektive para describir la manera en que algunas pinturas del segundo estilo «wrap around the inside corners of the room», ${ }^{36}$ sugiriendo con ello la posibilidad de que se adoptasen varios sistemas de perspectivas conscientemente coordinados entre sí, cuyo cometido radicaba en orientar las miradas de espectadores y visitantes hacia una dirección u otra. ${ }^{37}$ Durante la década de los sesenta y setenta del siglo veinte, nuevos descubrimientos arqueológicos sacaron a la luz extraordinarios ejemplos pictóricos - pertenecientes, precisamente, al Architekturstil- que avivaron el debate en torno a la perspectiva geométrica, como fueron los hallados de la celebérrima Casa de Augusto ${ }^{38}$ en Roma y la Villa A de Oplontis en Torre Annunziata. Finalmente, los estudios desde la década de los noventa se han centrado en el análisis e interpretación de las evidencias literarias, como

34. Phyllis W. Lehmann: Roman Wall Paintings from Boscoreale in the Metropolitan Museum of Art, Archaeological Institute of America, Cambridge, 1953, pp. 146-152. Idea que retomaría con fuerza el estudioso berlinés JosEF ENGEMANN en su Architekturdarstellungen des frühen Zweiten Stils. Illusionistische römische Wandmalerei der ersten Phase und ihre Vorbilder in der realen Architektur, Kerle, Heidelberg, 1967, defendiendo que, efectivamente, su aplicación respondió a una elección artística intencionada.

35. Heinrich Drerup, 1959.

36. Philip Stinson, 2011, p. 407.

37. BuRKHARDT WeSENBERG: «Zur asymmetrischen Perspektive in der Wandedekoration des zweiten pompejanischen Stils», Marburger Winckelmannsprogramm, (1968), pp. 102-109.

38. Gianfilippo Carettoni: «La decorazione pittorica della Casa di Augusto sul Palatino», Mitteilungen des Deutschen Archäeologischen Instituts. Römische Abteilung, 90 (1983), pp. 373-419. 
demuestran las aportaciones de Richard Tobin, Rolf A. Tybout o Pierre Gros, ${ }^{39}$ así como en desarrollar las distintas funciones que las perspectivas halladas en la pintura pompeyana desempeñaron en el ordenamiento jerárquico no solo de las paredes desde un punto de vista formal o decorativo, creando distintos ámbitos o esquemas tripartitos, sino también de las distintas estructuras habitacionales de la casa romana. ${ }^{40}$ Específicamente, Tobin desestimó las opiniones de Panofsky, las cuales -apoyándose argumentalmente en el teorema 8 de la Optica de Euclides-, le habían llevado a concluir que las «classical optics, with its spherical vision and the (consequently) curved, inexact perspective derived from it, is antithetical to plane, central-point projection». ${ }^{41}$ Según Tobin, la teoría óptica euclidiana y la perspectiva lineal no serían tan antagónicas como el erudito alemán creía axiomáticamente ${ }^{42}$ pues en su artículo defiende la posibilidad de que los pintores antiguos hallaran «a systematic method of central-point projection proceeding from and without violation to the curvilinear premise of classical optics». ${ }^{43} \mathrm{El}$ teorema 8 de Euclides establece una diferencia entre la imagen que es registrada por

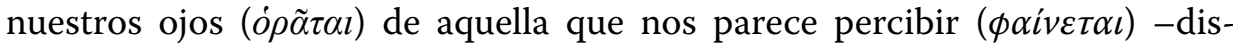
tinción de la que, por cierto, se nutrió toda la óptica clásica-. Tanto la visión de la imagen vista, como la percepción de la imagen aparente, dependen de un ángulo visual común, situación que los artistas desde el periodo clásico solventaron mediante métodos de corrección óptica entre los que, de acuerdo con Tobin, se podría contar «a central-point perspective that derived from and conformed to, curvilinear theory». ${ }^{44}$

39. Rolf A. Түвоuт: «Die Perspektive bei Vitruv: zwei Überlieferungen von scaenographia», en $H$. Geertman, J. J. De Jong (eds.): Munus non ingratum: Proceedings of the International Symposium on Vitruvius' De Architectura and the Hellenistic and Republican Architecture, Stichting Bulletin Antieke Beschaving, Leiden, 1989, pp. 55-68; Richard TobIN: "Ancient Perspective and Euclid's Optics», Journal of the Warburg Courtauld Institutes, 53 (1990), pp. 14-41; Pierre Gros, 2008, pp. 5-18.

40. Daniela Scagliarini Corlàita: «Spazio e decorazione nella pittura pompeiana», Palladio, 24-26 (1974-1976), pp. 3-44; ANDREW WAllaCE-HADrill: «The social structure of the Roman house», Papers of the British School at Rome, 56 (1988), pp. 43-97; JoHn R. ClaRKE: The houses of Roman Italy, $100 B C-A D$ 250: ritual, espace and decoration, University of California Press, Berkeley, 1991; PENELOPE M. Allison: «The relationship between wall-decoration and room-type in Pompeian houses: Casa della Caccia Antica», Journal Of Roman Archaeology, 5 (1992), pp. 235-249; Penelope M. Allison: «How do we identify the use of space in Roman housing?», en ERIC M. MOORMAN (ed.): Functional and spatial analysis of wall painting. Proceedings of the 5th International Congress, Babesch, Amsterdam, 1993, pp. 1-8; RoLF A. Tyвоuт: «Malerei und Raumfunktion im zweiten Stil», en Eric M. Moorman (ed.): Functional and spatial analysis of wall painting. Proceedings of the 5th International Congress, Stichting Babesch, Leiden, 1993, pp. 38-50; ANDrew WAllace-HAdrill: Houses and Society in Pompeii and Herculaneum, Princeton University Press, Princeton, 1994; Rolf A. Tyвout, 2001, pp. 33-56.

41. Richard Tobin, 1990, p. 16.

42. En primer lugar, Tobin expuso que Panofsky se sirvió de una versión errónea del octavo teorema de la Optica de Euclides para postular sus hipótesis, interpretado en la tradición de la Optica de Teón de Alejandría (335-405 d. C.). Seguidamente, aclara que la versión idónea es la edición crítica realizada por J. L. Heiberg en 1895, en la que se sugiere la puesta en práctica de la proyección geométrica o lineal en la perspectiva antigua.

43. Richard Tobin, 1990, p. 17.

44. Ibid., p. 26. 
Recientemente, Philip Stinson ha realizado un pequeño pero significativo y exhaustivo estudio acerca de los sistemas de perspectiva empleados en las «perspectivas arquitectónicas» del segundo estilo, para el cual analizó los parámetros físicos y sociales del espacio doméstico romano. Sus investigaciones le llevaron a identificar dos tipos diferentes de perspectiva: la convergente y la paralela, estableciendo, además, que una variante de la primera facilitó la evolución y uso de sistemas múltiples de perspectiva convergente. Proponiendo que los pintores campanos y romanos del siglo i a. C. emplearon una «flexible and adaptable form of perspective» ${ }^{45}$. La convergence perspective de Stinson se asemeja a nuestra moderna perspectiva geométrica; no obstante, su construcción -más que basarse en la abstracta noción de infinito a que nos conduce el punto de fuga en la perspectiva lineal- consiste en hacer converger el punto de vista del espectador en un área o eje determinado, por lo que obtendremos no uno, sino varios puntos de fuga, por así expresarlo sintéticamente; por otro lado, en la parallel perspective- concepto emparentado, como se recordará, con la assymetrische Perspektive de Wesenberg-, las ortogonales se disponen paralelas las unas a las otras, de tal modo que no se produce convergencia alguna, incluso si la intención del pintor hubiese sido la de otorgar una impresión general de convergencia. Pese a que ambas suelen aparecer no solo conjuntamente, sino también perfectamente coordinadas en la superficie muraria pictórica, cada sistema concreto empleado sirve para sus propios propósitos. La perspectiva convergente dio lugar a una peculiar variante perspectívica caracterizada por el uso de lo que Stinson denominó sistemas de convergencia múltiples (multiple convergence systems), cuyo entendimiento se esclarecerá más fácilmente cuando nos apoyemos en ejemplos visuales.

\section{El Segundo estilo. La PUESTA EN ESCENA ARQUitectónica}

El origen del Architekturstil es fácilmente rastreable desde principios del siglo I a. C. en Pompeya aunque, realmente, surge un poco antes en Roma, concretamente en la Casa de los Grifos. Es ahora bajo este estilo cuando la vanguardia de la pintura parietal adopta, tras varios titubeos y préstamos pictóricos extranjeros, un nuevo foco geográfico: la península itálica. ${ }^{46}$ Remitiéndonos al esquema o desarrollo interno del estilo desarrollado por Beyen, es posible compartimentar el segundo estilo en dos grandes fases, subdivididas, a su vez, en otras tres y dos subfases respectivamente:

45. Id.

46. Tal y como se desprende de las aportaciones perspectívicas desde la Grecia clásica, podemos afirmar que el segundo estilo es una de las tantas notorias aportaciones del arte romano a la historia del arte universal. Pese a que a menudo se ha afirmado que este se originó en el Mediterráneo oriental, y alcanzó su madurez en Italia. Esta suerte de difusionismo nos parece ridículo, máxime cuando «such examples as are known from Greece and the East are relatively simple, the equivalent of the very earliest phases in Italy; and their dating need in no case be earlier than the mid first century B. C.; indeed they may have been inspired from Italy», en Roger LiNG, 1991, p. 23. 
a) La fase I (erste Phase) sobrevino, aproximadamente, desde tiempos de Lucio Cornelio Sila hasta el fin de la época de Julio César (ca. 80-40 a. C.). En ella se produjo un progresivo avance desde una concepción o tratamiento «cerrado» $\mathbf{o}$ «plano» del muro hacia la apertura ilusoria de la superficie parietal. Proceso que se desarrolló paulatinamente al compás de sus distintas subfases: la fase IA (die erste Stufe), la fase IB (die zweite Stufe) y la fase IC (dritte Stufe).

b) La fase II (zweite Phase), desarrollada desde el Segundo Triunvirato hasta la primera parte del reinado de Augusto (ca. 40-15 a. C.), implicó un retorno al «muro cerrado» pero concebido desde una nueva óptica, pues el foco visual empezó a constituirlo un cuadro central; mientras que se dio paso a una nueva estética en la que el diseño y el color tuvieron una clara preeminencia sobre la apariencia de la realidad. Dentro de esta fase se suceden la IIA y la IIB.

Fase IA

El gran logro de la fase IA con respecto al primer estilo consistió en su capacidad de imitar las formas arquitectónicas por medios puramente pictóricos, pues se eliminó la aplicación de toda traza o relieve de stucco, de tal modo que la profundidad se sugirió tan solo por medio de recursos puramente pictóricos. En este sentido, el primer ejemplo maduro de la fase IA lo encarna la citada Casa de los Grifos (100-90 a. C.), en el monte Palatino, en donde se introdujo el segundo plano plenamente definido en las habitaciones 4 y 2 . Estancias en las que es posible observar el asentamiento de la división tripartita nuclear del segundo estilo (zócalo, zona central, zona superior), así como la obediencia jerárquica que guardan las líneas de perspectiva con respecto al eje central de la composición de cada pared. Por lo que parece existir un intento de dirigir las miradas de los espectadores hacia la pared del fondo de la estancia, pues los podia han sido creados utilizando la perspectiva paralela, cuyas ortogonales se dirigen hacia el que parece ser el eje central [Fig. 1].

\section{Fase IB}

En la fase IB el principio de centralización perspectívico se acentúa, al compás del énfasis de los avances y retrocesos de los elementos, los cuales crecen y son más complejos. Mientras que en la parte alta del muro, asistimos a las primeras sugerencias de un mundo visible más allá de la pared.

La Villa de los Misterios, en Pompeya, presenta un conjunto pictórico tradicionalmente fechado ha. 60-50 a. C. ${ }^{47}$ en el que surgen nuevas soluciones al típico muro cerrado de ortostatos o screen wall: como es el intento de materializar, por medios netamente pictóricos, la ilusión de una estancia 


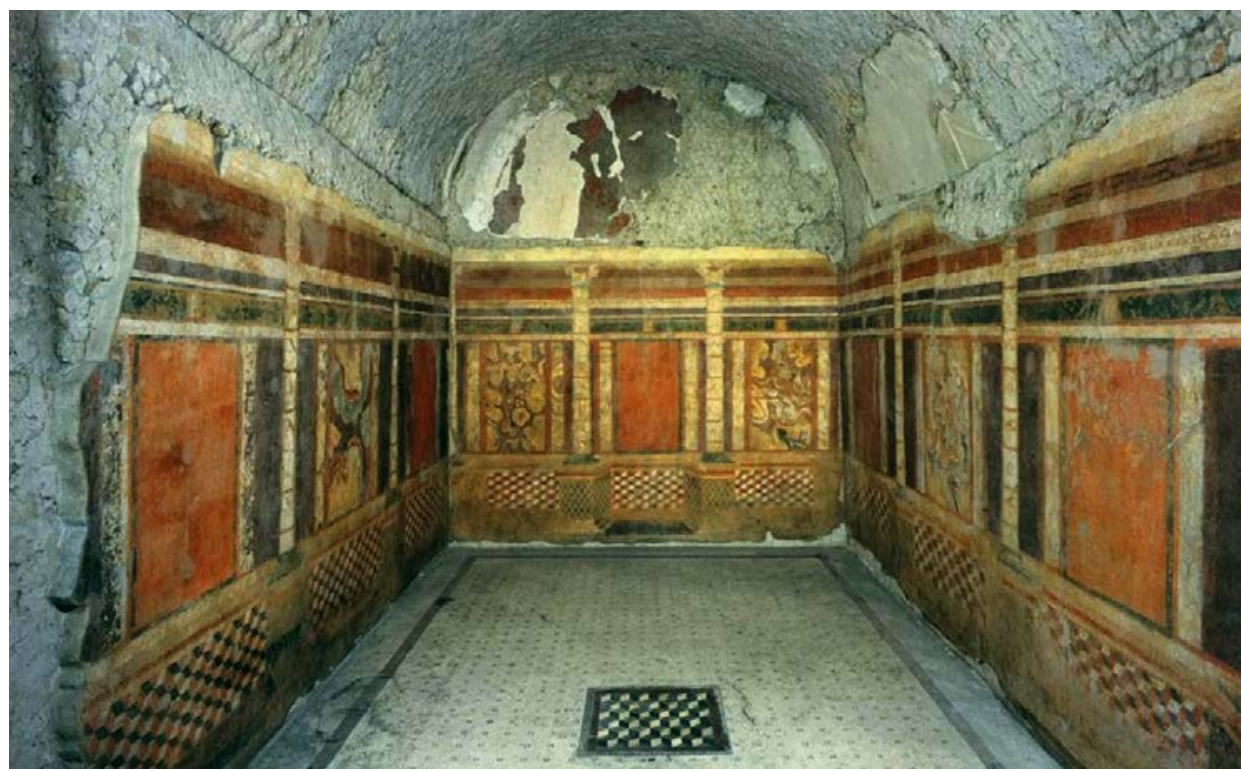

Fig. 1. Habitación II, Casa de los Grifos (100-90 a. C.), Roma. Antiquarium del Palatino

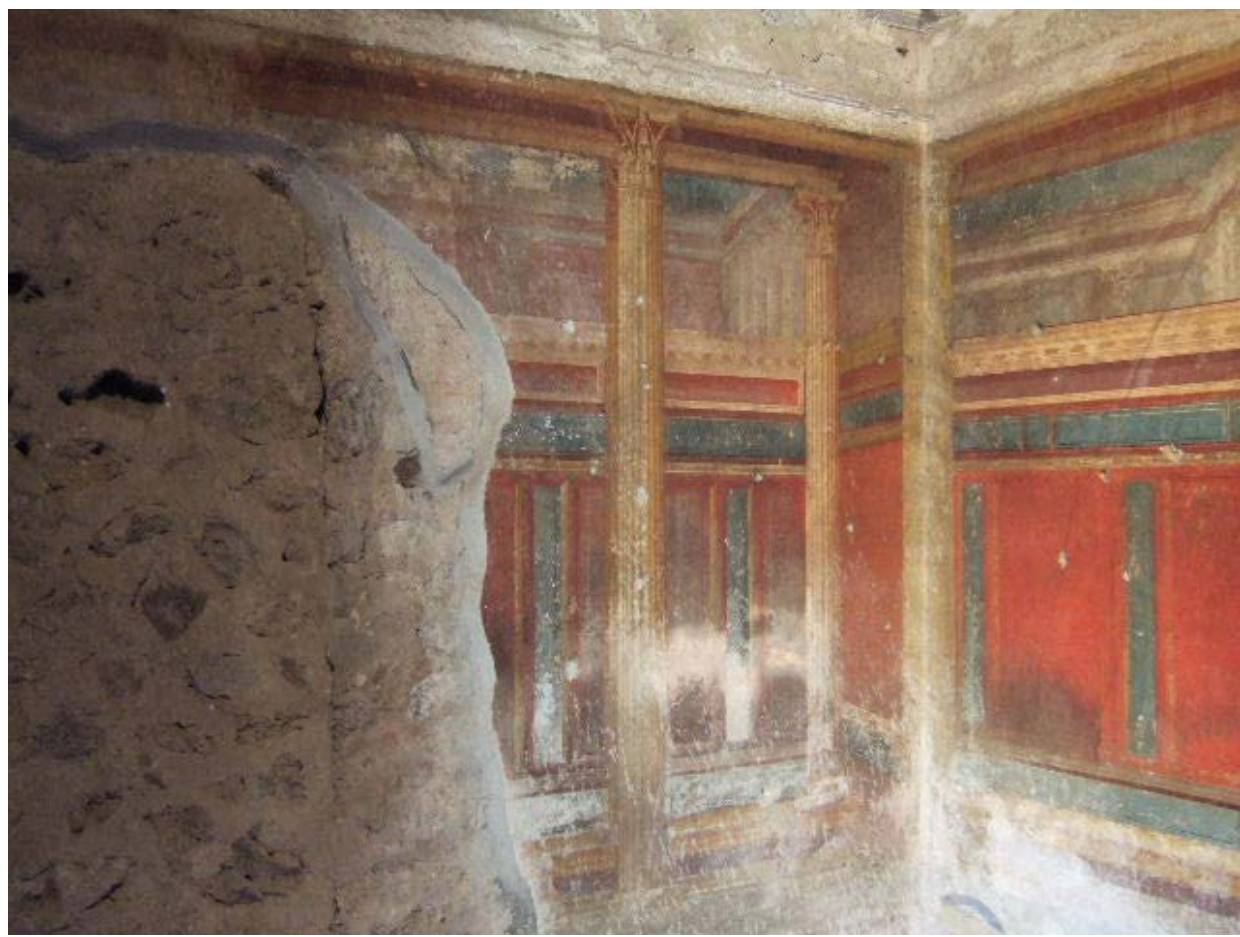

Fig. 2. Detalle de la esquina noroeste de la alcoba B, cubiculum 8, Villa de los Misterios, en Pompeya, ha. 60-50 a. C. (LiNg, 1991, fig. 22) 
a través. Esta prolongación espacial, creada a base de muros cerrados y una techumbre casetonada en perspectiva, adopta en sus variantes más complejas vistas a patios columnados que se abren a cielos azulados, tal y como se aprecia en la esquina noroeste de la alcoba B del cubiculum 8 [Fig. 2]. Tal proeza se amolda a los principios de la convergence perspective, reservada para las zonas altas del muro. En contraposición, en los muros contiguos a dicho fragmento murario, la perspectiva es más bien asimétrica.

La habitación 16 es la auténtica pièce de résistance de la fase IB, siendo las pinturas de la alcoba A una de las más estudiadas de toda la pintura pompeyana por el sofisticado complejo perspectívico utilizado. En ella un entablamento recorre la totalidad de la estancia, siendo sujetado por pilastras ubicadas en las esquinas. La pared del fondo $\mathrm{u}$ oriental de dicha alcoba presenta cuatro columnas, detrás de las cuales se ha dispuesto el screen wall, del que surge un entablamento corrido que se proyecta -hacia el plano del espectador- justo en los tramos soportados por dichas columnas estriadas. ${ }^{48}$ Detrás de ellas, aparecen pilastras en clara correspondencia, que interrumpen la monotonía imperante de la zona central. Sobre ellas se ha dispuesto una pequeña cornisa con ménsulas en perspectiva paralela que discurre, ininterrumpidamente, detrás de las pilastras. No obstante, la zona central no constituye el término espacial más lejano, pues del entablamento que sobresale parten tres arcos de medio punto que se prolongan -por medio de bóvedas de cañón con sus respectivos casetones en perspectiva- hacia un fondo imaginario [Fig. 3].

Las perspectivas se organizan en torno a un eje central vertical: en la parte superior, tanto la columnata corintia descrita como las bóvedas de cañón casetonadas se construyen a partir de líneas de convergencia ortogonales. Las zonas altas del muro parecen recibir un cuidado y tratamiento espacial mayor y mejor que las de otras partes del muro. Las ortogonales de la zona superior, si bien proporcionan un efecto tridimensional notable, no convergen en el mismo punto, sino en una pequeña zona «that corresponds to the size of a fist or silghtly larger and not on a single point»». ${ }^{49}$ Por el contrario, el zócalo con pedestales de la zona inferior genera una impresión volumétrica menor, pues sus ortogonales no se unen en un área de convergencia, sino que aparecen representadas paralelas las unas a las otras.

En la alcoba B [Fig. 4] se aprecia un virtuosismo de perspectivas similar, mientras que el famoso oecus, cuyas pinturas megalográficas de temática mistérica han venido a denominar la presente villa, carece de este elaborado despliegue de perspectivas, pese a sus efectos grandiosos de trompe-l'oeil. Por lo demás, sigue el familiar esquema arquitectónico de que venimos hablando: podium que se proyecta hacia nuestro plano sobre el que se disponen las

48. Esta combinación o juego arquitectónico de entrantes y recesos de entablamentos no solo se traspondrá, poco después, al campo de la arquitectura real propiamente dicho -recuérdese al respecto las columnas proyectadas del Foro de Nerva o Transitorio del siglo i d. C.-, sino que fue un leitmotiv de la gramática arquitectónica de las posesiones orientales helenizadas del Imperio romano.

49. Philip Stinson, 2011, p. 409. 


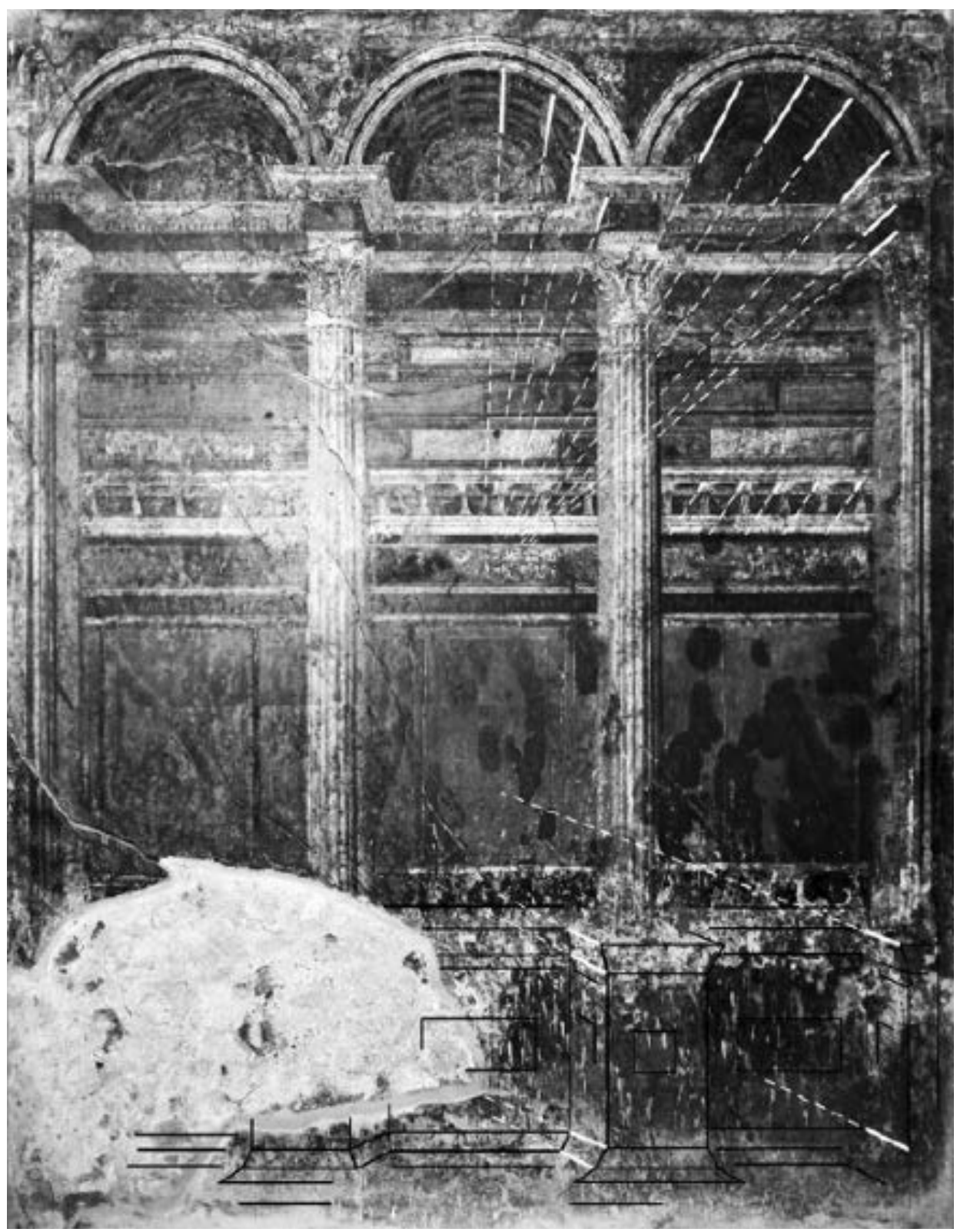

Fig. 3. Pared oriental de la alcoba A, habitación 16, Villa de los Misterios, en Pompeya, ha. 6050 a. C., donde se señalan los sistemas de perspectiva empleados (STINSON, 2011, fig. 3)

figuras, seguido de un muro compuesto a base de paneles de ortostatos, coronado por varios frisos de meandros, bloques pétreos veteados y uno con cupidos cazando entre vides. 


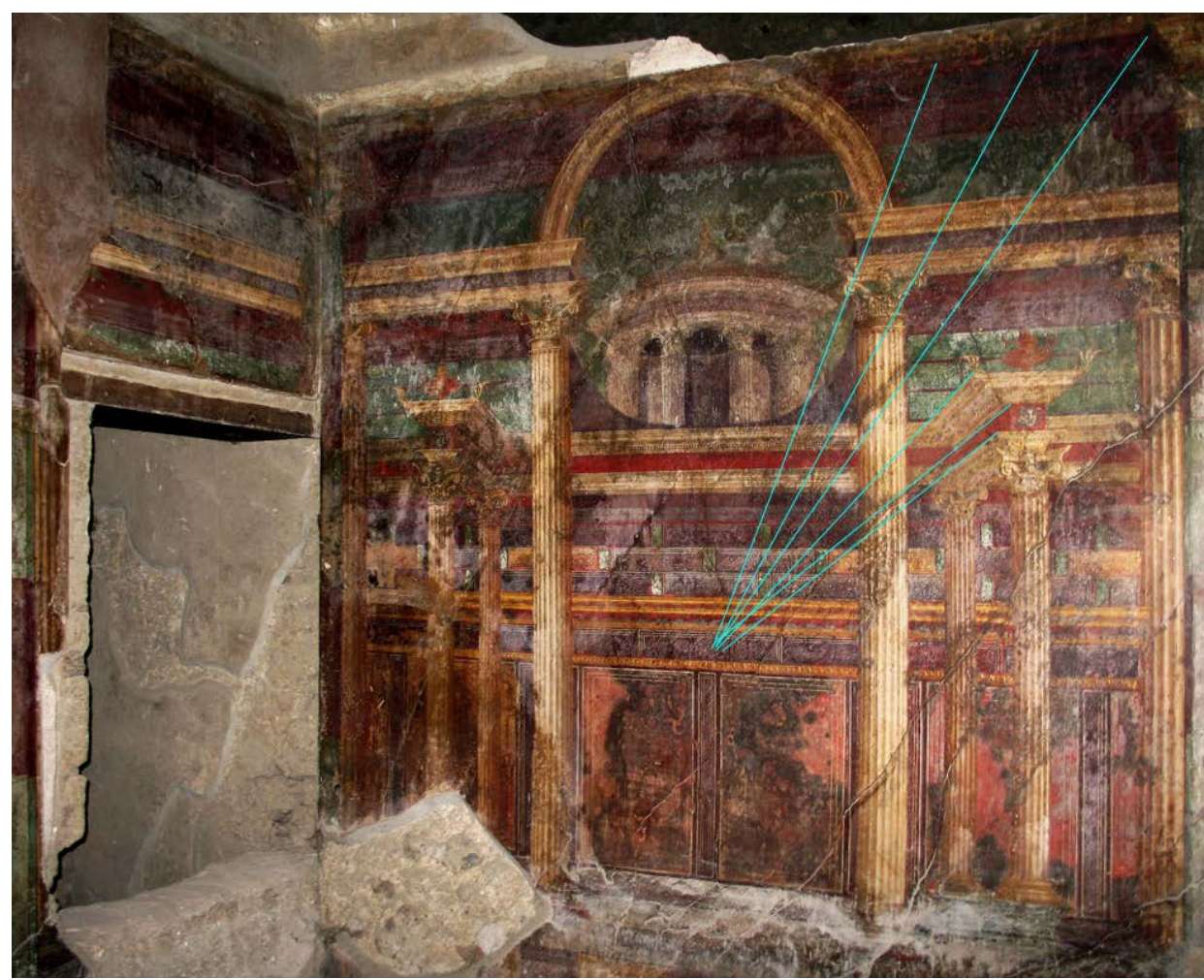

Fig. 4. Pared meridional de la alcoba B, habitación o cubiculum 16, Villa de los Misterios, en Pompeya, ha. 60-50 a. C., donde se señalan los sistemas de perspectiva empleados (elaboración propia según STINSON, 2011, fig. 5)

Fase IC

Los notables progresos hasta aquí descritos fueron magistralmente superados por la fase subsiguiente, en la que se engloban dos de los recintos más impresionantes a nivel pictórico no solo dentro de su subgrupo, sino de todos los restos de pintura parietal de la Antigüedad grecorromana preservados, hablamos de la Villa A o de Popea, en Torre Annunziata (Oplontis) y la Villa de Publius Fannius Synistor, en Boscoreale. Por lo que respecta a su cronología, asunto que ha generado un arduo debate que se extiende hasta nuestros días, ${ }^{50}$ tomaremos la conciliadora datación de 50-40 a. C. para ambas. Aunque analizaremos solo algunos ejemplos de la primera.

En estos ejemplos el muro se ha disuelto completamente a merced del ilusionismo arquitectónico, dando paso a todo un despliegue de elaboradas

50. Rolf A. Tybout establece como terminus post quem el año 59 a. C., creyendo que se realizaron poco después de dicha fecha (Rolf A. Tyвout, 2001, pp. 33-56.); según Paul Zanker oscilan entre 30-25 a. C.; mientras que Roger Ling propone la década c. 50-40 (Roger LiNG, 1991, pp. 28-31). 
arquitecturas que proporcionan un aspecto de realidad abrumador; asimismo, la gramática arquitectónica y decorativa de la fase inmediatamente anterior continúa, a saber: pantallas de columnas en un primer término, que se proyectan hacia afuera gracias al retranqueo del entablamento que soportan, y del que parten arcos de medio punto que se prolongan por los términos siguientes mediante bóvedas de cañón que presentan casetones en su interior; las consabidas vistas de tholoi que aparecen dentro de un patio porticado, frontones triangulares rotos en su lado mayor, puertas flanqueadas por dos columnas que se convierten en el núcleo focal del sistema, etc.

Cinco son las habitaciones de la Villa de Popea destacables decoradas en el segundo estilo pompeyano. Aunque sus pinturas son más elaboradas y mayores en tamaño que las preservadas en la villa anterior, ambas comparten la misma distribución de los sistemas de perspectiva: el convergente para las zonas murarias más elevadas, donde suelen ubicarse los asuntos o representaciones más impresionantes e importantes; y el paralelo en los niveles inferiores, cercanos al suelo.

De las cinco, la habitación 14 (triclinium) -cuyos muros este y oeste presentan una decoración y composición gemela-, constituye, quizá, el ejemplo de perspectiva más complejo [Fig. 5] de todo el Architekturstil. Así se evidencia en el muro occidental, en donde se dan tres sistemas de perspectiva convergente: ${ }^{51}$ por un lado, las ortogonales que parten del entablamento proyectado de las dos columnas centrales corintias que aparecen en primer término, convergen en el clípeo; las que proceden del par de columnatas que ocupan, también, una posición central pero al fondo -y que parecen cerrar los dos lados de un patiolo hacen justo encima del tondo; finalmente, las del entablamento sujetado por columnas toscanas, de la arquería que sobre él se ha dispuesto y de los pilares amarillos que discurren tras las arcos de medio punto laterales, convergen debajo de la puerta lígnea [Fig. 6].

Sin embargo, la vista más impresionante se encuentra en el muro este del oecus (habitación 15), donde el muro se abre en una inusitada expansión a través de aberturas que se multiplican por doquier. No obstante, a diferencia del triclinium 14, las pinturas de esta estancia solo emplean un sistema de convergencia para regular la inmensa composición que ocupa casi la totalidad de la altura de la misma; mientras que en la zona inferior cercana al suelo, a pesar de su pésimo estado de conservación, utiliza nuevamente la perspectiva paralela [Fig. 7].

51. Denominación otorgada por Philip Stinson (multiple convergence systems), referida a la existencia de varios puntos de fuga dentro de una composición o multiple vanishing points. Estos sistemas de convergencia múltiples no deben confundirse con la famosa «perspectiva de raspa de pez» promulgada por Panofsky, la cual surge como resultado del uso excesivo de la perspectiva paralela y que - pese a abundar, sobre todo, en las zonas altas del tercer y cuarto estilo pompeyano- puede decirse que estos «fishbone patterns (...) occur wherever parallel perspective is used, including the lower parts of Second Style Roman wall paintings», en Philip Stinson, 2011, p. 412; ERwin PANOFSKY, 2010, pp. 21-28. De lo que se desprende que la perspectiva convergente es un rasgo exclusivo del segundo estilo pompeyano. 


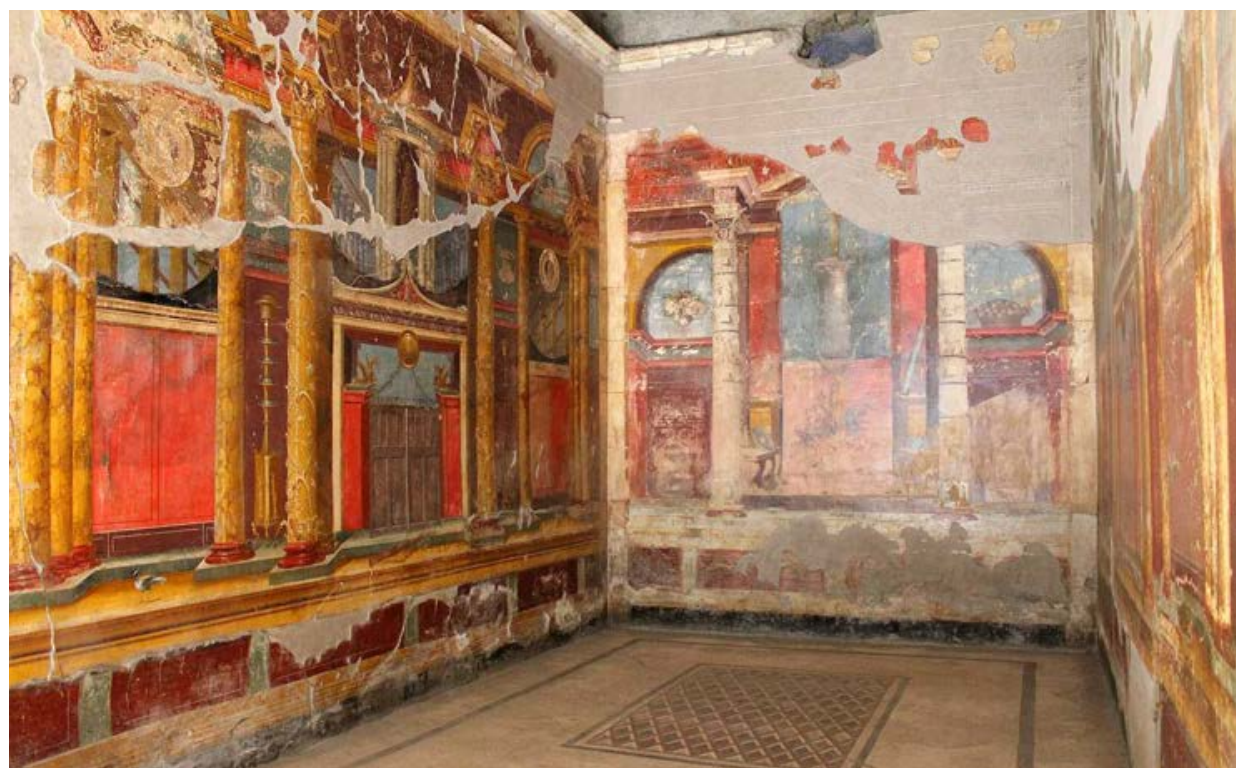

Fig. 5. Vista de la habitación 14 (triclinium), Villa de Popea en Oplontis (Torre Annunziata), siglo I a. C.

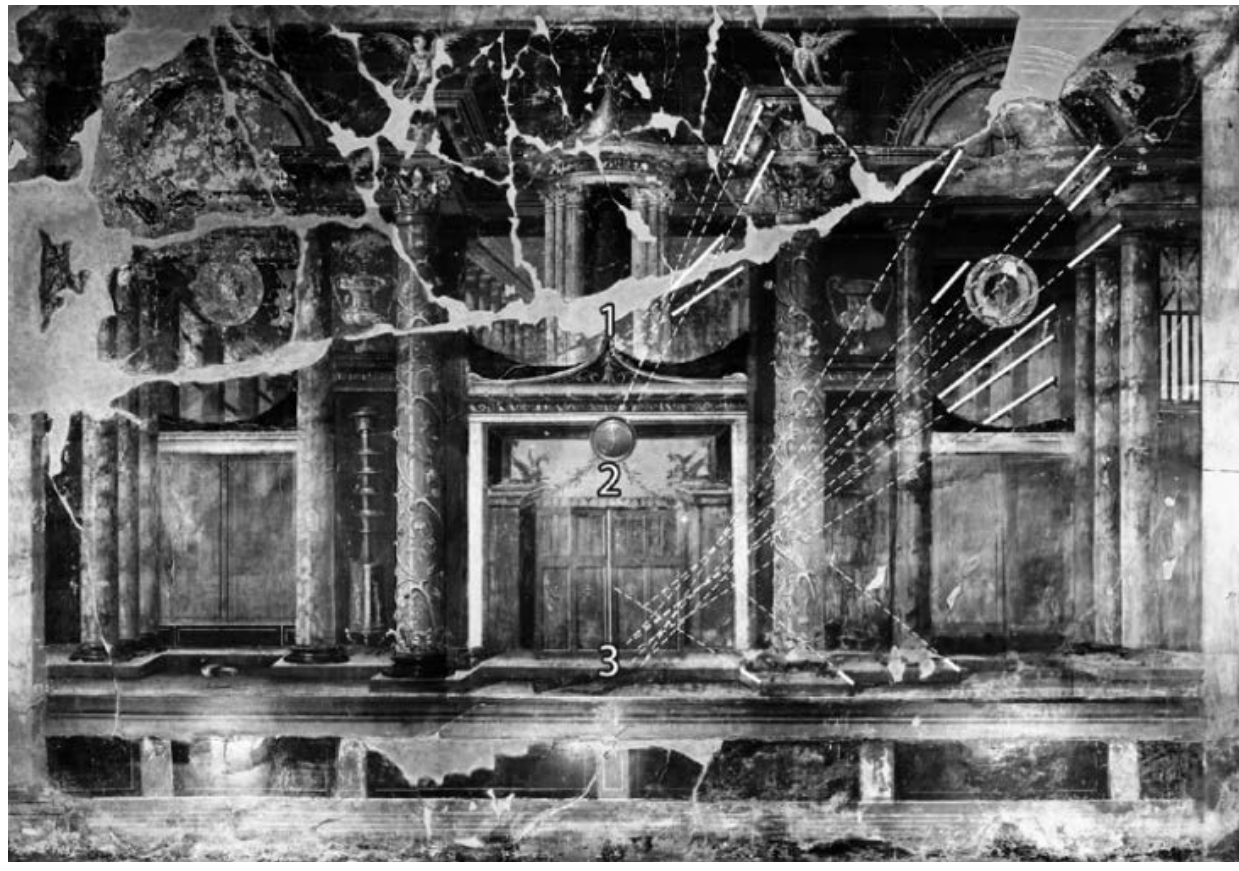

Fig. 6. Muro occidental de la alcoba B, habitación 14 (triclinium), Villa de Popea, en Oplontis, siglo i a. C., donde se señalan los sistemas de perspectiva empleados (STINSON, 2011, fig. 7) 


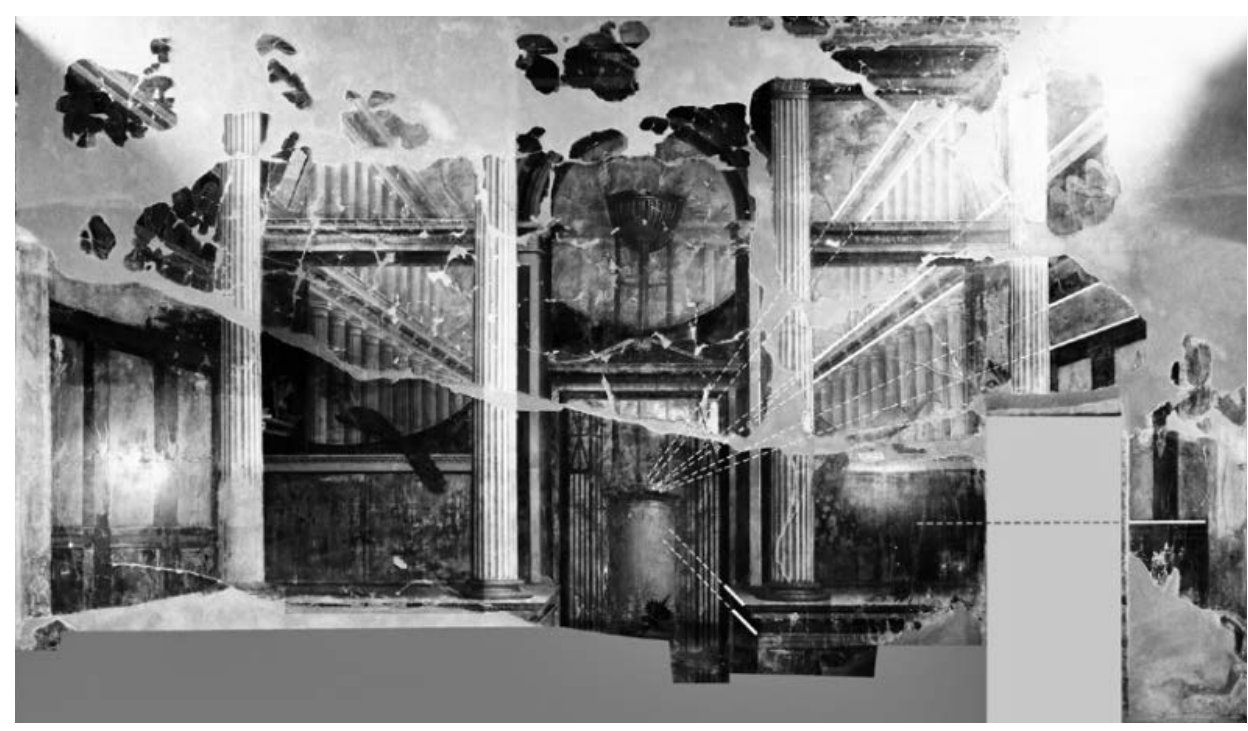

Fig. 7. Sistemas de perspectiva empleados en el muro este del oecus (habitación 15), Villa de Popea, en Oplontis, siglo I a. C. (Stinson, 2011, fig. 8)

Fase IIA

En la fase IIA se fue imponiendo gradualmente el principio del muro cerrado. Fechable entre finales de la década de los 40-30 a. C. aproximadamente, tiene en las pinturas de la pompeyana Casa del Criptopórtico las mejores muestras de dicho cambio.

En el frigidarium (habitación 20), así como en la habitación que lo antecede, se han hallado fragmentos parietales que siguen el esquema de perspectivas usados en Oplontis y en el triclinum de Boscoreale. ${ }^{52}$ Las paredes norte y sur son iguales en composición: en ambas se representa una estructura arquitectónica de dos niveles que parece formar el frente o fachada de una doble columnata; asimismo, la presencia de máscaras teatrales introduce asociaciones escenográficas; dos cariátides coronan la zona central de la columnata del segundo nivel, flanqueando un inmenso trípode. Sin embargo, la parte baja del muro meridional se interrumpe por la puerta que da acceso desde la antecámara al frigidarium.

El frente arquitectónico proporciona a la estructura una fuerte impresión de realidad, evocando una entidad arquitectónica unitaria; no obstante, los dos niveles de la estructura presentan sendos sistemas de perspectiva convergente,

52. Es decir, perspectivas que siguen esquemas más o menos centralizados, a los cuales se le suman la presencia de estructuras que se proyectan y retroceden alternadamente, columnatas que actúan como telón de fondo y fórmulas arquitectónicas carentes de funcionalidad alguna. 


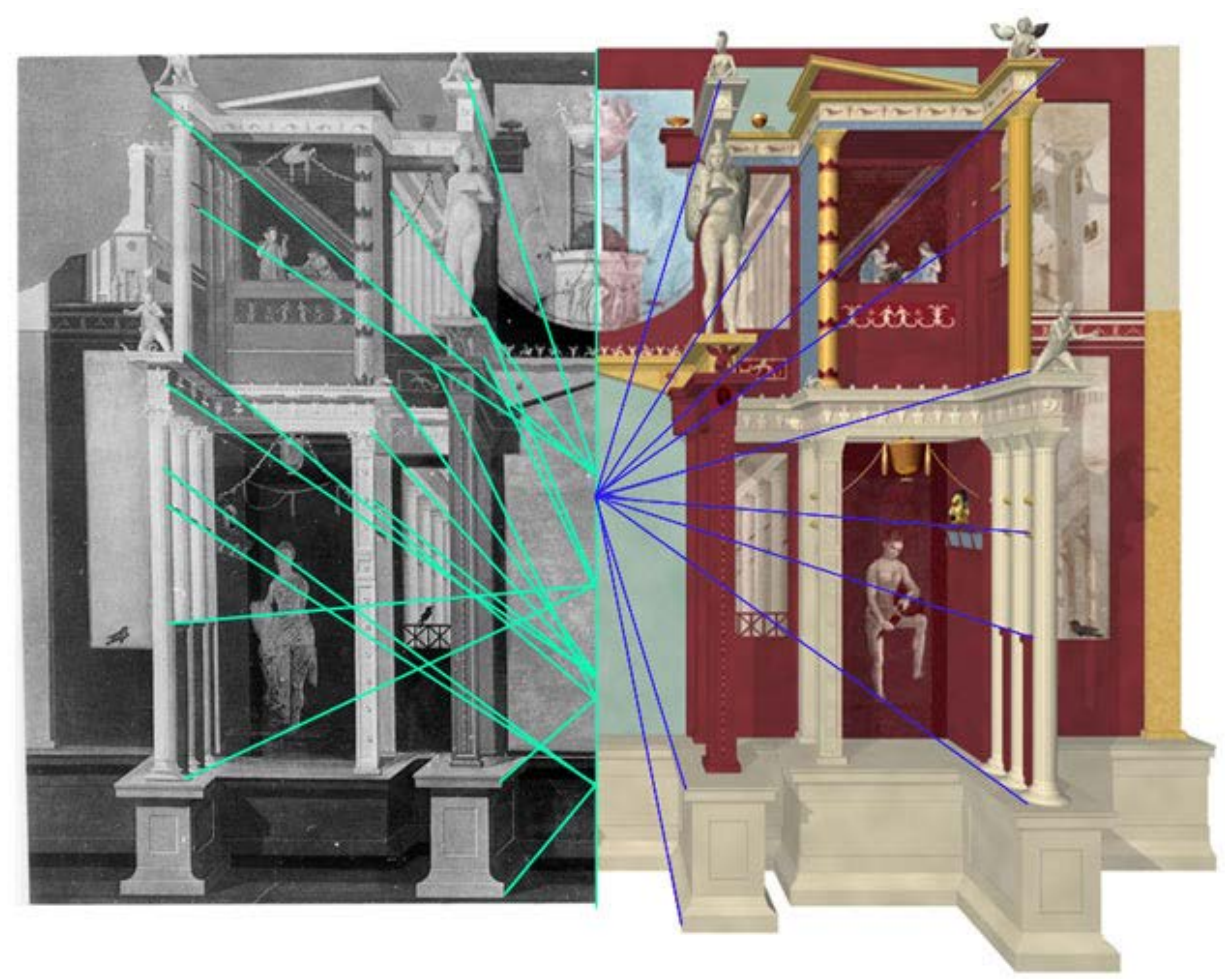

Fig. 8. Reconstrucción virtual comparativa en que se muestra la composición corregida (dcha.), de acuerdo con la perspectiva geométrica, del muro norte de la habitación 20 (frigidarium), Casa del Criptopórtico, Pompeya, siglo i a. C. (Blazeby, 2003, The Skenographia Project)

cuyas ortogonales desembocan en varios puntos de fuga a lo largo de un eje axial; mientras que la zona inferior utiliza la perspectiva paralela, la cual, por sus propias características, guarda menores concomitancias con la realidad material. A propósito de este ejemplo, Alan Little realizó una reconstrucción del mismo adoptando una perspectiva geométrica pura [Fig. 8] y defendió que esta representación pretendía evocar la idiosincrasia estructural de los teatros, de ahí que incorporase al diseño original las puertas laterales que permitían la entrada y salida de los actores del escenario..$^{53}$

\section{Fase IIB}

Ya durante la fase IIB (fines década de los 30-20 a. C.) se aprecia el comienzo de la disolución del ilusionismo arquitectónico: columnas y demás elementos

53. Véase Alan M. Little: Roman Perspective Painting and the Ancient Stage, Wheaton, Maryland, 1971, lámina IX. 
arquitectónicos pierden consistencia y realidad, sus formas se diluyen, a la vez que se enfatiza el gusto por las superficies planas, el diseño ornamental basado en formas vegetales, y la presencia de grandes imágenes centrales que tienden a dominar el esquema compositivo. Entre las propiedades romanas de Augusto, en el lado sureste del monte Palatino, destaca un complejo habitacional adyacente y alineado al Templo de Apolo que Augusto había ordenado erigir en 36 a. C. pero que se terminó en 28 a. C., momento en que se habría de fechar el conjunto pictórico que alberga, el cual ha pasado a llamarse tradicionalmente como «Casa de Augusto». Construida a gran escala en tres niveles sucesivos y decorada con pinturas similares a las del segundo estilo vistas en Pompeya. Muchas habitaciones presentan composiciones trufadas de diseños arquitectónicos de evidente inspiración teatral, ${ }^{54}$ como se ve en el muro meridional y occidental de la estancia número 5 (la habitación de las Máscaras).

Habitación cuyas pinturas muestran las características inherentes a los sistemas de perspectiva empleados en Campania, así lo evidencian las cuatro paredes que conforman dicha habitación, que comparten una estructura tripartita basada en pabellones que se proyectan y pantallas murarias en rojo cinabrio que soportan máscaras en sus huecos. No obstante, las columnas y los pilares sustentantes se han vuelto más ligeros, las aberturas del muro no revelan ya un espacio exterior sino pequeños habitáculos -a excepción del central, que se abre a un paisaje sacro-idílico de blanquecinas tonalidades-, aparece un uso hedonista del color (amarillo brillante y bermellón); la presencia de acroteria y demás seres de difícil denominación -que, sin pretensión de realidad alguna, parecen simular ser pequeñas figurillas broncíneas y que coronan los vértices arquitectónicos-, se acentúa [Fig. 9].

Compositivamente el muro norte y sur de la habitación de las Máscaras son prácticamente idénticos. En el sur las ortogonales que parten de las ligeras estructuras arquitectónicas convergen en la zona media del eje central, cuya axialidad resalta el elemento vertical apreciable en el panel central. Por el contrario, ortogonales paralelas dominan las zonas inferiores ocupadas por el zócalo, tal y como vienen haciendo en incontables ejemplos campanos. Como se aprecia en los cuatro muros que conforman la habitación, la regularidad y simetría de las ortogonales indican un preciso y coordinado esquema perspectívico. Asimismo, encontramos fragmentos pictóricos en los muros oeste y este que presentan sistemas de convergencia. A pesar de la casi unánime valoración por parte de la comunidad académica de que los ejemplos pictóricos de la habitación de las Máscaras constituyen una prueba fehaciente

54. Las pinturas murales de la habitación de las Máscaras, al igual que otras estancias de la Casa de Augusto y de la residencia de Livia en el Palatino, parecen evocar la arquitectura teatral romana primigenia, compuesta a base de elementos estructurales lígneos, y cuya estructura tripartita (regia, sección central y hospitalia o alas) no solo se aprecia en sus equivalentes pétreos, sino también en el esquema compositivo de estas pinturas: en todas ellas se representa una estructura arquitectónica que presenta un receso central y dos alas flanqueándola que presentan sendas puertas abiertas. 


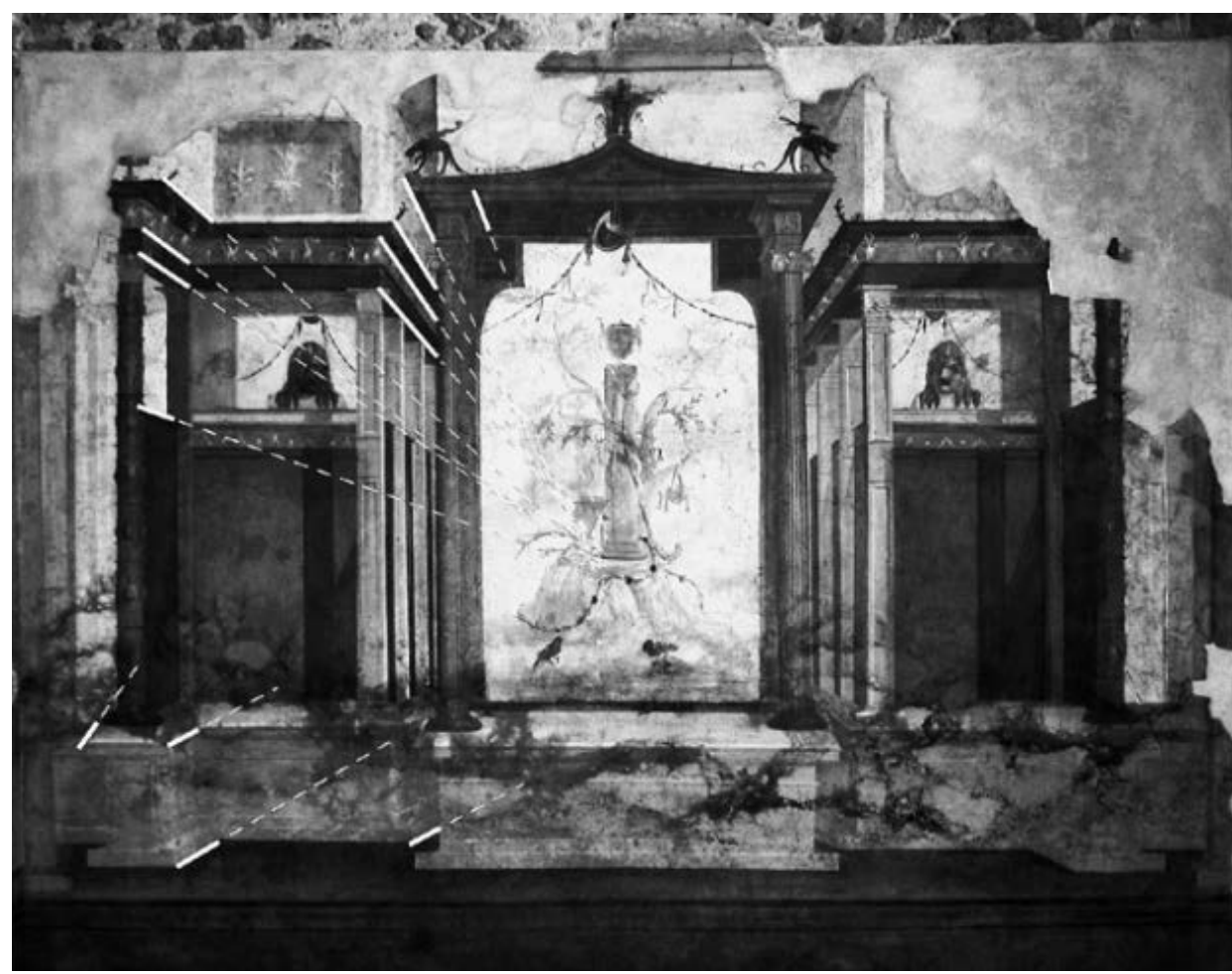

Fig. 9. Sistemas de perspectiva empleados en el muro occidental de la habitación 5, Casa de Augusto, en el monte Palatino, Roma, siglo I a. C. (Stinson, 2011, fig. 13)

del conocimiento de la perspectiva científica en la antigüedad, lo cierto es que siguen el mismo patrón perspectívico que se ha visto en las pinturas antedichas.

Los frescos hallados en una casa bajo la Villa Farnesina (ca. 20 a. C., Museo Massimo alle Terme, Roma), en la ribera derecha del Tíber, constituyen el último ejemplo del Architekturstil. Así como el primero de los triunfos del esquema bidimensional monocromático y del predominio de las superficies planas que están en la base de la gestación del tercer estilo. Los cubicula $\mathrm{B}$ y $\mathrm{D}$ poseen esquemas arquitectónicos en que la perspectiva, aunque presente, parece servir como mero marco para las escenas figurativas. Aquí la importancia ha recaído en la riqueza cromática: bermellones, amarillos, blancos, negros y azules forman un rítmico diseño a base de bloques, los cuales poseen marcos en colores contrastantes y que, asimismo, están decorados con todo un surtido de motivos vegetalizantes. En otras estancias hay un predominio unívoco de un solo color, como en la habitación E, dominada por el blanco, cuyo podium se proyecta pero su aspecto, más que simular volumen alguno, diríase de trazado lineal. Como contrapartida, en el triclinium (C) hallamos uno de los primeros fondos negros de la pintura pompeyana, en 


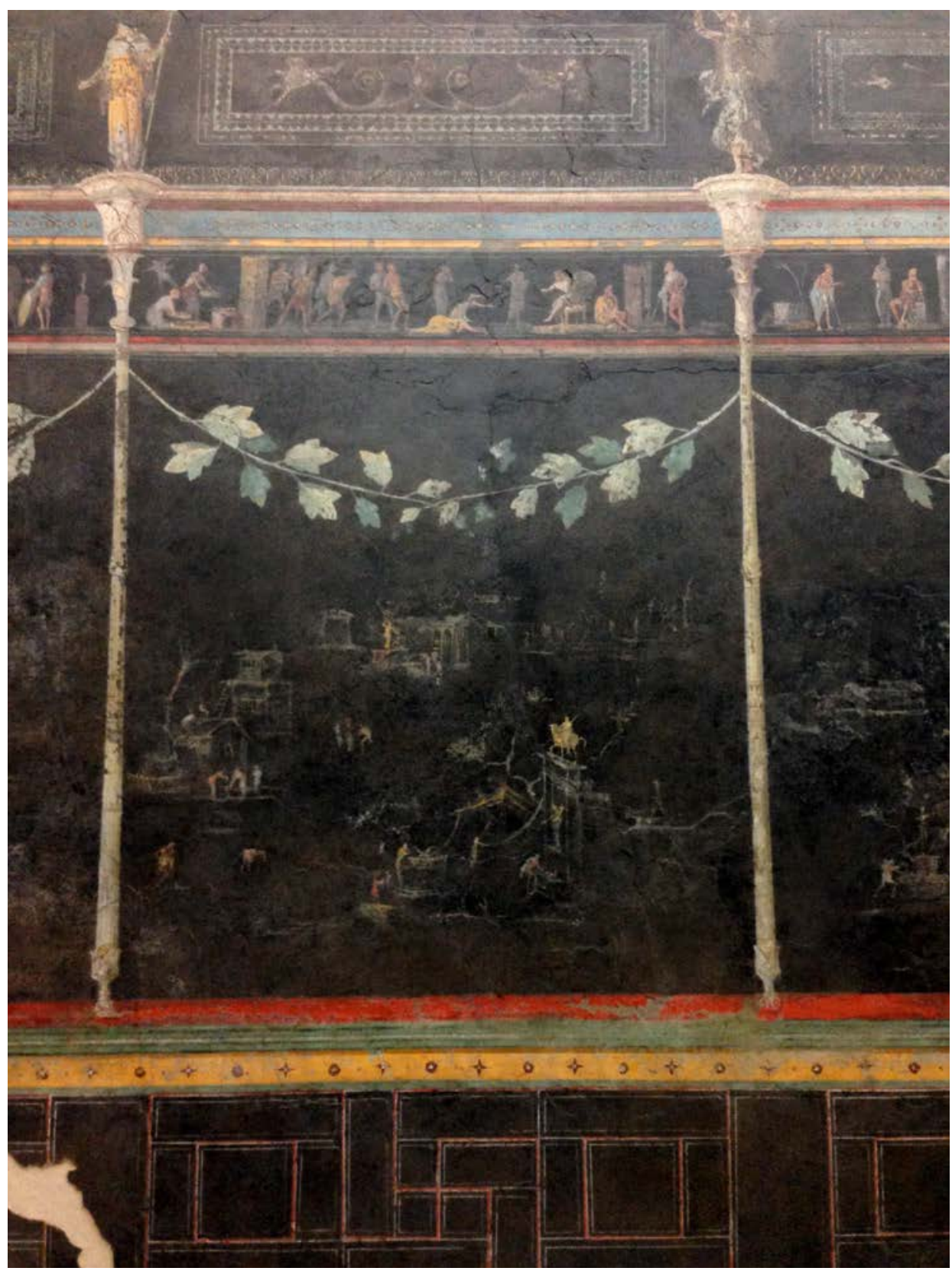

Fig. 10. Detalle de una pintura de la habitación C (triclinium), Villa Farnesina, ca. 20 a. C., Roma, Museo Massimo alle Terme, Roma

donde casi toda la ilusión de profundidad ha sido suprimida: el podium es plano, decorado con líneas que forman un meandro coronado por bandas amarillas y turquesas, las columnas son meros candelabra coronados por estatuillas y el entablamento ha sido reducido a pequeñas bandas de color 
rojo, azul y amarillo [Fig. 10]. En definitiva, elementos que escandalizarían a Vitruvio y que anuncian el esquema paratáctico que trajo consigo el ocaso del «estilo arquitectónico».

\section{Conclusión}

El análisis realizado en ejemplos campanos y romanos del segundo estilo ha revelado el uso de dos tipos principales de perspectiva empleados: el convergente y el paralelo, los cuales se organizan de acuerdo a un eje central. Constituyendo la parcela de aparición habitual del primero las zonas superiores del muro, mientras que del segundo lo son las inferiores. Sistemas de convergencia múltiples, en los que las ortogonales convergen no en uno sino en varios puntos de fuga, aparecen profusamente en la Villa A de Oplontis; otro rasgo importante es la manera en la que las ortogonales, si bien dan la impresión de encontrarse en un único punto espacial, lo cierto es que lo hacen, siempre, en una área reducida. En definitiva, la idea de abrir pictóricamente una pared por medio de un sistema óptico de ilusión espacial convincente no tuvo precedentes consistentes y documentados en la pintura mural antigua anterior al segundo estilo, logro que a menudo se compara con el que se adjudicó a Masaccio siglos después por sus admirados frescos de la Capilla Brancacci, en la florentina iglesia de Santa Maria del Carmine. Quizá, lo sorprendente de ello, sea nuestra todavía dificultad de identificar a simple vista la ausencia de una perspectiva lineal, máxime cuando nos encontramos en una cultura eminentemente visual, multimedia, acostumbrados como estamos a la visualización, por ejemplo, de imágenes fotográficas, en que se recoge una «perspectiva correcta». Los ejemplos analizados permiten concluir que, más o menos, cada elemento representado sigue su propio punto de vista óptimo, como si el pintor quisiese mostrarnos la representación o vista canónica de los objetos..$^{55}$

Pese a que la extendida opinión de muchos especialistas de que la perspectiva romana ha de necesariamente derivar de un complejo y elaborado sistema perspectívico griego creado con anterioridad, lo cierto es que ni existe un consenso unánime entre todas las autoridades en la materia, ni es posible asumir, a día de hoy, que los conocimientos de perspectiva practicados en las pinturas de escenarios griegas (skenographia) fuesen desconocidos por la cultura romana. Las interferencias culturales entre Grecia y Roma durante el periodo republicano, especialmente intensificadas durante sus dos últimos siglos, trajeron consigo la adaptación de estas ideas y su posterior reelaboración por parte de los artistas romanos, capaces de asimilar los presupuestos

55. Efecto similar al que aparece en los vasos pintados campanos del siglo iv a. C., en donde los objetos y arquitecturas se representan aisladamente, sin compenetración espacial alguna con la escena en sí, en Jocelyn Penny Small, 2003, p. 125. 
pseudocientíficos y ópticos inherentes a la perspectiva y de aplicarlos creando complejos esquemas tridimensionales.

No obstante, la perspectiva convergente no tenía cabida en las nuevas modas dictaminadas por la sociedad romana, materializadas en el tercer y cuarto estilos, siendo absolutamente prescindible para los nuevos cometidos visuales de las intrínsecas composiciones que dominaron, sobre todo, el último de los grandes estilos pictóricos romanos. Aún hoy los lamentos de Vitruvio por la aparición del gusto fantasioso y contra natura resuenan entre los muros decorados en el tercer estilo que tanto denostaba el arquitecto augusteo. Quejas paradójicas si se tiene en cuenta que fueron sus comitentes -a saber, la familia Julio-Claudia con Augusto a la cabeza-, precisamente, quienes abanderaron la vanguardia pictórica por la que tanta nostalgia sentía. Sin embargo, fue en las pinturas del cuarto estilo, concretamente en las vistas arquitectónicas que solían situarse en lo más alto del muro -lugar privilegiado en que se colocaban las perspectivas convergentes más audaces del Architekturstil-, donde se dieron algunos de los avances en el campo de la todavía incipiente perspectiva atmosférica.

\section{BibLIOGRAFÍA}

Allison, P. M.: «The relationship between wall-decoration and roomtype in Pompeian houses: Casa della Caccia Antica», Journal Of Roman Archaeology, 5 (1992), pp. 235-249.

- «How do we identify the use of space in Roman housing?», en Moorman, E. M. (ed.): Functional and spatial analysis of wall painting. Proceedings of the 5th International Congress, Babesch, Ámsterdam, 1993, pp. 1-8.

Bastet, F. L., De Vos, M.: Proposta per una classificazione del terzo stile pompeiano. Staatsuitgeverij, The Hague, 1979.

BEYEN, H. G.: Die pompejanische Wanddekoration vom zweiten bis zum vierten Stil, The Hague, 1938/1960.

- «Die antike Zentralperspektive», Jahrbuch des deutschen archäologischen Instituts, 54 (1939), pp. 47-72.

Carettoni, G.: «La decorazione pittorica della Casa di Augusto sul Palatino», Mitteilungen des Deutschen Archäeologischen Instituts. Römische Abteilung, 90 (1983), pp. 373-419.

ClARKE, J. R.: The houses of Roman Italy, 100 BC - AD 250: ritual, espace and decoration, University of California Press, Berkeley, 1991.

Drerup, H.: «Bildraum und Realraum in der römischen Architektur», Mitteilungen des Deutschen Archäologischen Instituts. Römische Abteilung, 66 (1959), pp. 145-174.

EDgERTON, S. Y.: The Renaissance rediscovery of linear perspective, Harper and Row, Nueva York, 1976. 
EHRHARDT, W: Stilgeschichtliche Untersuchungen an römischen Wandmalereien. Von der späten Republik bis zur Zeit Neros, Von Zabern, Mainz, 1987.

Elvira, M. Á.: «Aportaciones al estudio de la perspectiva lineal en la Grecia del siglo v a. C.», Archivo Español de Arqueología, 56, 147-148 (1983), pp. 45-66.

- Manual de arte griego. Obras y artistas de la Antigua Grecia, Sílex, Madrid, 2013.

Engemann, J.: Architekturdarstellungen des frühen Zweiten Stils. Illusionistische römische Wandmalerei der ersten Phase und ihre Vorbilder in der realen Architektur, Kerle, Heidelberg, 1967.

Gioseffi, D.: Perspectiva artificialis. Per la storia della prospettiva spigolature e appunti, Instituto di Storia dell'Arte Antica e Moderna, Trieste, 1957.

Gros, P.: «The Theory and Practice of Perspective in Vitruvio's De architectura», en Carpo, M., Lemerle, F. (eds.): Perspective, Projections and Design. Technologies of Architectural Representation, Routledge, Nueva York, 2008, pp. 5-18.

LehmanN, P. W.: Roman Wall Paintings from Boscoreale in the Metropolitan Museum of Art, Archaeological Institute of America, Cambridge, 1953.

Ling, R.: Roman Painting, Cambridge, University Press Cambridge, 1951.

Litt le, A. M.: Roman Perspective Painting and the Ancient Stage, Wheaton, Maryland, 1971.

Mau, A.: Geschichte der decorativen Wandmalerei in Pompeji, Druck und Verlag von G. Reimer, Berlín, 1882.

Panofsky, E.: Die Perspektive als «Symbolische Form», B. G. Teubner, LeipzigBerlín, 1927.

- La perspectiva como «forma simbólica», Tusquets, Barcelona, 2010.

SCAgliarini, D. C.: «Spazio e decorazione nella pittura pompeiana», Palladio, 24-26 (1974-1976), pp. 3-44.

Sinisgalli, R.: Perspective in the Visual Culture of Classical Antiquity, University Press, Cambridge, 2012.

SMAll, J. P.: «Skenographia in brief», en Harrison, G. W., Liapis, V. (eds.): Performance in Greek and Roman Theatre, Brill, Leiden, 2003, pp. 111-130.

Stinson, P.: «Perspective Systems in Roman Second Style Wall Painting», Journal of the Archaeological Institut of America, 115, 3 (2011), pp. 403-426.

Strocka, V. M.: «Pompejanische Nebenzimmer», en Andreae, B., Kyrieleis, H. (ed.): Neue Forschungen in Pompeji un den anderen von Vesuvausbruch 70 n.Chr, verschütteten Städten, Recklinghausen, 1975, pp. 101-114.

TATARKIEWICZ, W.: Historia de la estética I: La estética antigua, Akal, Madrid, 1987.

Toвin, R.: «Ancient Perspective and Euclid's Optics», Journal of the Warburg Courtauld Institutes, 53 (1990), pp. 14-41. 
Tyвоut, R. A.: «Die Perspektive bei Vitruv: zwei Überlieferungen von scaenographia», en Geertman, H., De Jong, J. J. (eds.): Munus non ingratum: Proceedings of the International Symposium on Vitruvius' De Architectura and the Hellenistic and Republican Architecture, Stichting Bulletin Antieke Beschaving, Leiden, 1989b, pp. 55-68.

- «Malerei und Raumfunktion im zweiten Stil», en Moorman, E. M (ed.): Functional and spatial analysis of wall painting. Proceedings of the 5th International Congress, Stichting Babesch, Leiden, 1993, pp. 38-50.

- «Roman Wall-Painting and Social Significance», Journal of Roman Archaeology, 14 (2001), pp. 33-56.

Wallace-Hadrill, A.: «The social structure of the Roman house», Papers of the British School at Rome, 56 (1988), pp. 43-97.

- «Patronage in Roman society: from Republic to Empire», en WallaceHadrill, A. (ed.): Patronage in ancient society, Routledge, Londres, 1989, pp. 63-88.

- Houses and Society in Pompeii and Herculaneum, Princeton University Press, Princeton, 1994.

Wesenberg, B.: «Zur asymmetrischen Perspektive in der Wandedekoration des zweiten pompejanischen Stils», Marburger Winckelmannsprogramm, (1968), pp. 102-109.

Artículos y publicaciones en línea

Blazeby, M.: The Skenographia Projec. King's Visualisation Lab, (2003), http://www.skenographia.cch.kcl.ac.uk/crypto/plan.html. (Consultado: 3 de mayo de 2015)

\section{Fuentes literarias}

Euclides: Optica (Ortiz, P. (trad.): Óptica, Gredos, Madrid, 2000).

LuCRETIUS, T.: De rerum natura.

Vitruvius, M.: De Architectura libri decem (Oliver, J. L. (trad.): Los diez libros de Arquitectura, Alianza Editorial, Madrid, 1995). 